Original Research

\title{
Self-Efficacy and the Competency of Nursing Students Toward the Implementation of Evidence-Based Practice
}

\section{Yusshy Kurnia Herliani, Hasniatisari Harun, Anita Setyawati and Kusman Ibrahim}

Faculty of Nursing, Universitas Padjadjaran, West Java, Indonesia

\begin{abstract}
Introduction: Professional nurses should have adequate competency in order to apply Evidence Based Practice (EBP) in their nursing care. However, many nurses provide nursing care based on traditions, habits and personal experience. Less confidence in the feeling of nurses about their competency when employing EBP could inhibit successful EBP implementation in nursing care. Therefore, introducing and applying EBP during clinical placements in the Ners program is essential to form a professional attitude and to provide a basic level of experience when applying EBP in patient care. However, the self-efficacy and competence of the students when applying EBP has not yet been evaluated properly and there is little known about the nursing students' competences and self-efficacy toward EBP implementation during clinical practice. Thus, the study aims to describe the self-efficacy and competency of nursing students toward the implementation of EBP, while also investigating the relationship between self-efficacy and the competency of nursing students in the implementation of EBP.
\end{abstract}

Methods: This descriptive correlational study involved 120 nursing students who were actively registered on the Ners program 2016/2017. The data was collected by using the self-reporting Evidence-Based Practice Questionnaire (EBPQ), which was then analysed descriptively and inferentially using statistics.

Results: The results of this study revealed that more than half (55\%) of the participants had a high score of self-efficacy and almost half (49\%) were categorised as having a high competence when implementing EBP. The selfefficacy score was significantly correlated to the score of competency $(r=0.607$, $\mathrm{p}<0.01)$.

Conclusion: This study recommends that the development of the students' competence in implementing EBP is essential to promote self-efficacy when applying EBP, and vice versa.

\section{ARTICLE HISTORY}

Received: October 31, 2017

Accepted: June 05, 2018

\section{KEYWORDS}

competence; evidence-based practice; nursing student; selfefficacy

\section{CONTACT}

Yusshy Kurnia Herliani \yusshy.kurnia@unpad.ac.id $\doteq$ Faculty of Nursing, Universitas Padjadjaran, West Java, Indonesia

Cite this as: Herliani, Y., Harun, H., Setyawati, A., \& Ibrahim, K. (2018). Self-Efficacy and the Competency of Nursing Students toward the Implementation of Evidence-Based Practice. Jurnal Ners, 13(1), 50-56. doi:http://dx.doi.org/10.20473/in.v13i1.6359

\section{INTRODUCTION}

Nursing, as an integral part of the national health system, contributes to support the needs of the health services, since nurses spend the most time with patients to provide direct care (Sin \& Bliquez, 2017). Nurses, as the largest group of health care providers, have a significant role in promoting health care and providing better services for patients (Khammarnia, Mohammadi, Amani, Rezaeian, \& Setoodehzadeh, 2015). Nursing care is a physiological, psychological, social, cultural and spiritual service provided to the clients in order to address the actual or potential disruption of basic human needs. The future challenges faced by the nursing care services are global competition that requires professional nurses to provide effective problem solving, to ensure patient safety and quality nursing care (Aglen, 2016).

Professional nurses can be prepared through the Nursing Educational Program. The nursing educational program via a Bachelor's degree in Indonesia comprises of academic and clinical 
education (Ners Program). The Ners Program refers to the professional clinical education in the Bachelor's degree program, which is aimed at comprehensively building the students' abilities and attitude to make them a professional nurse through field and clinical learning experience (Suba \& Scruth, 2015). The Ners program in Indonesia is conducted after the student has completed the academic nursing education program in order to prepare the healthcare professional.

Nevertheless, many healthcare professionals still decide that clinical intervention is based on traditional practices, assumptions, personal experiences and individual beliefs and skills (Azmoude, Farkhondeh, Ahour, \& Kabirian, 2017). Therefore, the students of the Ners program should learn and practice the implementation of Evidencebased Practice (EBP) during their clinical practice. Evidence-based Practice (EBP) is a mechanism of nursing practice focused on providing safe and highquality patient care based on the evidence of research and professional expertise, rather than tradition, myths, hunches, advice from peers, or outdated books (Masters, 2015).

EBP implementation is essential for nurses in the clinical setting to effectively communicate with their patients and the healthcare team about the rationale for decision-making and care plans (Oh, Yang, Sung, Park, \& Chang, 2016). EBP has an integral role in providing high-quality patient care by encouraging problem-solving to make better healthcare decisions in health care implementation, based on recent best available research within the clinical context (Elham Azmoude et al., 2017). Unfortunately, many nurses cannot implement EBP in the clinical setting since they feel insecure about their competency in employing the EBP skills that are used in their decision-making process as a professional (Oh et al., 2016).

Nursing education institutions have the responsibility to prepare the nursing students in terms of EBP mastery (E. Azmoude, F. Farkhondeh, M. Ahour, \& M. Kabirian, 2017). Teaching EBP to undergraduate students is essential as a major preparation to perform the professional role of a Registered Nurse (Sin \& Bliquez, 2017). However, a previous study reported that undergraduate nursing students experienced a lack of support and the opportunity to practice EBP, and also a lack of confidence when it came to independently utilising EBP (Ryan, 2016). A previous study related to evidence-based practice was conducted by Legita in 2012, on 66 General Hospital nurses in Pontianak. The results showed that the nurses did not have sufficient preparation in terms of knowledge and the habit of doing research and reading in support of the implementation (Legita, 2012). Moreover, previous research conducted among midwives in East Iran also revealed that the level of knowledge and confidence in one's ability to apply EBP were correlated with its effective implementation (Elham Azmoude et al., 2017).
Another significant variable affecting the implementation of EBP is self-efficacy. Self-efficacy is defined as an individual's belief in their own ability to perform specific skills (Elham Azmoude et al., 2017). Numerous studies have reported that the majority of nurses did not have the desired level of self-efficacy in the implementation of EBP (Farokhzadian, Khajouei, \& Ahmadian, 2015). In addition, the majority of the nurses $(60 \%)$ were not familiar with the concept of EBP, and their self-efficacy skills related to EBP were poor (Farokhzadian et al., 2015).

The students of the Ners program of the Faculty of Nursing Universitas Padjadjaran have learned about EBP theory in the second year of the Bachelor's degree nursing program. They exercised analysing the case and solving the nursing problem using EBP analysis. However, the self-efficacy and competence of the students in applying EBP has not been evaluated properly and there is little known about the nursing students' competences and their self-efficacy toward EBP implementation during clinical practice. The study aims to describe self-efficacy and the competency of the nursing students toward implementation of EBP, and also to investigate the relationship between self-efficacy and the competency of the nursing students in the implementation of EBP.

\section{MATERIALS AND METHODS}

This study was a descriptive correlational study. The sample of this study was made up of 120 nursing students who had completed the Ners program at the Nursing Faculty of Universitas Padjadjaran. Total sampling was used as the sampling procedure of this study. All of the participants were approached to ascertain their willingness to participate in the study. Then, the researcher explained to the potential participants the purpose of the study, gained their informed consent, and outlined the procedure, risks, benefits, and confidentiality. The participants had the right to refuse to participate in the study or to withdraw at any time without any negative consequences. Quantitative data collection was performed by asking the students to fill in the questionnaire.

Evidence-Based Practice Questionnaire (EBPQ) was the self-reported instrument used in this study to assess competence and self-efficacy when applying evidence-based practice. EBPQ was composed of 24 items, each with a 7 point rating scale. The internal consistency was 0.87 (Upton \& Upton, 2006). The filled questionnaires were returned directly, and then the researcher checked the questionnaires for completion, and coded the questionnaires to ensure the anonymity of the participants. This study was approved by the Research Ethics Committee of Faculty of Medicine, Universitas Padjadjaran No 861/UN6.C.10/PN/2017.

The data was analysed using descriptive and correlational statistics. Descriptive statistics were used to describe self-efficacy and competency of the 
Table 1. Frequency, percentage, mean, and standard deviations of the patients' demographic data $(n=120)$

\begin{tabular}{ccc}
\hline Characteristic & $\mathbf{N}$ & $\mathbf{\%}$ \\
\hline Age (range 21-45) & Mean $=25.53$ & SD $=5.79$ \\
\hline Gender & & 9.2 \\
Male & 11 & 90.8 \\
\hline Female & 109 & 80.0 \\
Regular & & 20.0 \\
Transfer & 96 & 19.2 \\
\hline Occupation & 24 & 80.8 \\
Nurse & & 13.3 \\
Fresh graduate & 23 & 79.2 \\
\hline$<3$ & 97 & 7.5 \\
\hline
\end{tabular}

Table 2. Mean score and standard deviation of students' competency in implementing EBP in clinical practice $\underline{(n=120)}$

\begin{tabular}{clcc}
\hline No & \multicolumn{1}{c}{ Competency } & M & SD \\
\hline 1 & Ability to identify gaps in your professional practice & 4.99 & 0.992 \\
2 & Ability to search new evidence & 4.93 & 0.968 \\
3 & Ability to obtain new evidence of nursing practice & 4.94 & 1.117 \\
4 & Ability to analyze evidence critically & 4.87 & 0.913 \\
5 & Ability to determine validity of evidence of nursing practice & 5.12 & 1.034 \\
6 & Ability to determine beneficial of invention in the literature & 5.36 & 1.019 \\
7 & Ability to update new evidence in clinical practice for patient & 4.86 & 1.311 \\
8 & Ability to apply evidence into practice & 5.39 & 1.189 \\
\hline
\end{tabular}

Table 3. Mean score and standard deviation of students' self-efficacy in implementing EBP in clinical practice $\underline{(n=120)}$

\begin{tabular}{clcc}
\multicolumn{1}{c}{ Self-Efficacy } & M & SD \\
\hline No & & 5.03 & 0.879 \\
2 & Ability to search new evidence & 4.91 & 0.789 \\
3 & Ability to identify gaps in your professional practice & 4.96 & 0.834 \\
4 & Ability to obtain new evidence of nursing practice & 4.79 & 0.849 \\
5 & Ability to determine validity of evidence of nursing practice & 4.76 & 0.889 \\
6 & Ability to determine beneficial of invention in the literature & 5.10 & 0.854 \\
7 & Ability to apply evidence into practice & 5.17 & 0.929 \\
\hline
\end{tabular}

Table 4. Mean, standard deviation, frequency, and percentage level of self-efficacy and competency in implementing EBP in clinical practice $(n=120)$

\begin{tabular}{|c|c|c|c|c|c|c|c|}
\hline & \multicolumn{2}{|c|}{ Low } & \multicolumn{2}{|c|}{ High } & \multirow{2}{*}{ Mean } & \multirow{2}{*}{ SD } & \multirow[t]{2}{*}{ Category } \\
\hline & $\mathbf{n}$ & $\%$ & $\mathbf{n}$ & $\%$ & & & \\
\hline Self-efficacy & 54 & 45.0 & 66 & 55.0 & 34.72 & 4.813 & High \\
\hline Competency & 62 & 51.7 & 58 & 48.3 & 40.47 & 5.930 & High \\
\hline
\end{tabular}

Table 5. Correlation ( $\mathrm{r}$ ) between self-efficacy and competency of nursing students in implementing EBP in clinical practice $(n=120)$

\begin{tabular}{cc}
\hline & Competency \\
\hline Self-efficacy & $0.607^{* *}$ \\
\hline$*$. Correlation is significant at the 0.01 level (2-tailed). &
\end{tabular}

sample by using frequency, percentage, mean, and standard deviation. Preliminary testing was done to meet the assumption of parametric testing prior to running the parametric tests. Pearson's productmoment correlation statistic ( $r$ ) was calculated to examine the relationship between self-efficacy and the competency of nursing students towards the implementation of evidence-based practice.

\section{RESULTS}

Most of the participants in this study were women (90.8\%), with an average age of 25.53 years, and ranging from 21 to 45 years. The majority of the participants were registered on the regular program (80\%). $79.2 \%$ of the participants had a GPA range from 3.0 to 3.5 . Table 2 presents that the mean competency scores in implementing EBP in clinical 
practice for all subscales were high (a score more than 3.5). The highest mean score of the sub-scales of competency in implementing EBP in clinical practice was the ability to apply evidence into practice $(\mathrm{M}=$ $5.39, \mathrm{SD}=1.189$ ) and the lowest mean score of the sub-scales of competency in implementing EBP in clinical practice was the ability to update based on new evidence in clinical practice for the benefit of the patient $(\mathrm{M}=4.86, \mathrm{SD}=1.311)$.

Table 3 depicts that the mean scores of selfefficacy in implementing EBP in clinical practice for all sub-scales was high (score above 3.5 ). The highest mean score of the sub-scales of self-efficacy in implementing EBP in clinical practice was the ability to apply evidence into practice $(M=5.17, S D=.929)$ and the lowest mean score of the sub-scales of selfefficacy in implementing EBP in clinical practice was to determine the validity of the evidence of nursing practice $(\mathrm{M}=4.76, \mathrm{SD}=.889)$.

Table 4 presents the mean, standard deviation, frequency, and percentage level of self-efficacy and competency in implementing EBP in clinical practice. The mean score of self-efficacy in implementing EBP was 34.72 ( $\mathrm{SD}=4.813$ ) with more than half $(55 \%)$ of the participants having a high score of self-efficacy. The mean score of competency in implementing EBP was $40.47(S D=5.930)$ with almost half $(49 \%)$ of the participants categorised as high competence for implementing EBP. Table 5 depicts the results of the bivariate correlational analysis using Pearson correlation coefficients ( $r$ ) between self-efficacy and competency in implementing EBP in clinical practice. The self-efficacy score was significantly correlated to the score of competency in implementing EBP ( $\mathrm{r}=$ $.607, \mathrm{p}<0.01$ ).

\section{DISCUSSION}

Most of the participants in this study were women (90.8\%), with an average age of 25.53 years, ranging from 21 to 45 years. The majority of the participants were registered on the regular program (80\%). There were $79.2 \%$ of the participants had GPA range from 3.0 to 3.5. The professional Nursing Educational Program (Ners Program) is a part of the nursing education program where the learning process occurs inside the clinic. The Ners Program refers to professional clinical placement program in bachelor degree program, which was aimed at comprehensively building the students' ability and attitude for them to become professional nurse through field and clinical learning experience (Suba \& Scruth, 2015). The Ners Program is conducted for one year in which the students get education and experience as a nurse in practice, whether in hospitals, community health centres, and various other health services. The Ners program students are those who have graduated from an academic program at Bachelor's degree and passed the examination of the General Registrar. The students will implement the prior knowledge that they had from the academic program. Student who complete the Ners Program receive the title of Ners (Upoyo \& Sumarwati, 2011).

Evidence-based practice (EBP) is defined as the delivery of health care that integrates the best evidence from well-designed studies with a patient's preferences and values, a clinician's expertise, and the patient's data to solve the problem (Melnyk, Gallagher-Ford, Long, \& Fineout-Overholt, 2014). EBP is defined as a framework to test, evaluate and apply research findings with the aim of improving nursing services to patients. There are seven steps in the EBP process: (a) cultivate a spirit of inquiry; (b) formulate an answerable question; (c) systematically search for the research evidence; (d) appraise the validity, relevance, and applicability of the research evidence; (e) integrate the research evidence with the clinical expertise of the practitioner and the wishes and desires of the patient and the family; (f) implement the EBP decision and evaluate the outcomes; and (g) disseminate the results (Melnyk, Fineout-Overholt, Stillwell, \& Williamson, 2010).

In the School of Nursing (SON), the first four steps are considered competencies for Bachelor's degree level. This is congruent with the Bachelor's degree competencies identified by the American Association of Colleges of Nursing (Stevens, 2009). The undergraduate curriculum in the SON is designed to assist students in their development of beginner's knowledge and skills with respect to the first four steps of the EBP process (Bloom, Olinzock, Radjenovic, \& Trice, 2013). The EBP project was designed based on the first four steps of the $5 \mathrm{~A}$ 's of the EBP process (ask, acquire, appraise, apply, assess) (Sin \& Bliquez, 2017). Asking a question is the first step of the EBP process. In the first step, the faculty framed questions in a scenario format instead of having the students form questions in order to enhance the clinical relevance of EBP in their daily practice. Formulating a question will yield the most suitable answer (Melnyk et al., 2010). The PICO technique (Patient, Intervention, Comparison, and Outcome) is used to frame and answer a clinical or health care-related question. The next important step in EBP is acquiring evidence. Selecting the most relevant evidence-based resources through literature searches or clinical guidelines is the activity of acquiring evidence (Melnyk et al., 2010; Sin \& Bliquez, 2017).

Then, appraising the evidence is the following step of acquiring evidence. In this section, the students should identify the best intervention from the synthesised literature by performing a critical evaluation of the evidence and its validity, relevance and feasibility, and then state the rationale for implementing the intervention (Melnyk et al., 2010; Sin \& Bliquez, 2017). The fourth step of the EBP process is applying evidence. This section is an implementation phase. Students should integrate research evidence with clinical experience, the patients' values and preferences (Melnyk et al., 2010). The last step is assessing the treatment outcome. EBP for Bachelor's degree level is limited to the third step. 
Since the EBP project is based on hypothetical clinical scenarios, the students are not asked to implement the intervention (Sin \& Bliquez, 2017). However, the competencies for the Ners Program students could be implemented up to assessing the treatment process with clinical instructor supervision.

\section{EBP Competencies}

The results of this study present that almost half (49\%) of the participants had a high score of competence in implementing EBP. The mean score of competency in implementing EBP in clinical practice was high. Competencies are defined as a system that supports health care professionals in providing highquality and safe care that consists of knowledge, psychomotor skills, and affective skills. Meanwhile, the nurses' competencies are the various patient care activities related to the critical issue of how practicing nurses approach decision-making (Melnyk et al., 2014). EBP competencies in this study include identifying gaps with professional practice, searching for new evidence, obtaining new evidence of nursing practice, analysing the evidence critically, determining the validity of the evidence, determining the benefits of invention in the literature, updating new evidence and applying the evidence into practice.

The highest mean score of the sub-scales of competency in implementing EBP in clinical practice was the ability to apply evidence into practice $(\mathrm{M}=$ $5.39, \mathrm{SD}=1.189$ ) and the lowest mean score of the sub-scales of competency in implementing EBP in clinical practice was the ability to update new evidence in clinical practice for the patient $(\mathrm{M}=4.86$, $\mathrm{SD}=1.311$ ). The most important supporting factor was mentoring by nurses who have adequate EBP experience, and the biggest barrier was the difficulty in judging the quality of research papers and reports. There was a moderate demand for training in all areas of EBP (J. Farokhzadian et al., 2015).

Students at Bachelor's degree level are introduced to EBP concepts to construct the foundation for the EBP process. They begin to identify the potential clinical questions as they become aware of current generalist nursing care problems. Using the EBP process to address practice issues, the students are guided through the sequence of steps to review research and to develop an EBP implementation plan (Hande, Williams, Robbins, Kennedy, \& Christenbery, 2017). Then, the students search the available scholarly literature to gain information related to the problems, and to critically appraise the information for determining a best intervention. The ability to apply interventions based on the most applicable evidence was also one of the highest priorities identified (Farokhzadian, Khajouei, \& Ahmadian, 2015). Interventions should provide the students with sufficient competences for implementing every step of EBP, with special focus on the implementation of evidence in patient care (Häggman-Laitila et al., 2016).

\section{Self-efficacy of EBP Implementation}

More than half of the participants (55\%) had a high score of self-efficacy in implementing EBP in clinical practice. The important variable affecting the implementation of EBP was self-efficacy, which is defined as an individual's belief in their own ability to execute skills at a designated level of performance (E. Azmoude et al., 2017). Self-efficacy (SE) is the belief that one is capable of performing a task or a desired action (Bandura, 1977). This study depicted that the mean scores of self-efficacy in implementing EBP in clinical practice were high. The self-efficacy of implementing EBP among the nursing students in this study included searching for new evidence, identifying gaps in professional practice, obtaining new evidence of nursing practices, analysing the evidence critically, determining the validity of the evidence, determining the benefits of intervention in the literature and applying the evidence into practice.

The highest mean score of the sub-scales of selfefficacy in implementing EBP in clinical practice was ability to apply evidence into practice $(\mathrm{M}=5.17, \mathrm{SD}=$ .929) and the lowest mean score of the sub-scales of self-efficacy in implementing EBP in clinical practice was to determine the validity of the evidence of nursing practice $(M=4.76, S D=.889)$. In contrast, several studies have revealed that the majority of healthcare professionals did not have the desired level of self-efficacy in the implementation of EBP (E. Azmoude et al., 2017). Previous research has also revealed that nurses have a low mean when it comes to their self-efficacy score (Farokhzadian et al., 2015).

Correspondingly, most clinical nurse specialists identified had no confidence in their ability to translate clinical problems into well-formulated questions (Mohsen, Safaan, \& Okby, 2016). In addition, a study reported that undergraduate nursing students experienced a lack of support and the opportunity to practice EBP and also a lack of confidence in employing EBP independently (Ryan, 2016).

The low self-efficacy score of the nurses and nursing students was identified as the result of a lack of personal experience in performing evidence-based practice in clinical practice. The personal mastery of performing tasks indicates that self-efficacy is essential in the process of behaviour change (Shinnick \& Woo, 2014). Furthermore, the low scores of self-efficacy among healthcare professionals in implementing EBP was related to several barriers at the individual level included a lack of time to read the literature $(83.7 \%)$, a lack of ability to work with a computer $(68.8 \%)$, and insufficient proficiency in the English language (62.0\%) (Khammarnia et al., 2015). Whereas the nursing students in this study could have more time to read the literature, have the ability to work with a computer and have a sufficient English proficiency. These factors are important to investigate in future research. 


\section{Correlation Findings}

The present study revealed that the self-efficacy score was significantly correlated to the score of competency in implementing EBP $(r=.607, \mathrm{p}<0.01)$. This result is in line with the previous research conducted among midwifes in Iran, which conveyed that self-efficacy scores were significantly correlated with practice (Azmoude et al., 2017). The positive association between the previous experience of EBP education and the self-efficacy in implementing EBP (SE-EBP) indicated that the exposure to EBP may increase the confidence in EBP of the clinical nurses (Oh et al., 2016). Furthermore, adopting EBP empowers nurses to become confident professionals, enabling the nurses to take legal accountability for their practice (Oh et al., 2016), resulting in the increase of EBP competencies.

A previous study revealed different aspects, in that education level had a significant relationship with competency in conducting EBP. The higher education levels of a person means better competency in performing EBP (Elysabeth, Libranty, \& Natalia, 2015). The study of Eizenberg (2010) revealed that education could lead a person to be skilled in finding the source of research, being organised and being professional in their work, increasing access-access to improve and implement practices based on EBP (Eizenberg, 2011). Previous research also observed that there was no significant relationship between self-efficacy and academic degree (Farokhzadian et al., 2015). However, the education levels of the participants in the present study were similar, since they had just finished the Ners Program. Therefore, the education level could not be compared.

In the present study, age, program, and working experience are not likely to be correlated with selfefficacy and competencies when conducting EBP.

This result is similar to the results of previous studies, revealing that the midwives who were older and had more working experience were not significantly more likely to have greater EBP knowledge, self-efficacy or practice (Farokhzadian et al., 2015).

\section{CONCLUSION}

The results of the study revealed that more than half of the participants had a high score of self-efficacy and almost half were categorised as having high competence in relation to implementing EBP. Moreover, the self-efficacy score was significantly correlated to the score of competency when it came to implementing EBP. Despite this study having a big sample population, the participants were only from one institution, so the results cannot be generalised. Therefore, future research should be involving nursing students from various nursing education institutions in order to investigate the factors affecting self-efficacy and competency in implementing EBP in clinical practice. In addition, this study recommends that the development of the students competence in implementing EBP is essential to promote self-efficacy in applying EBP, and vice versa.

We would like to express our deep appreciation and thanks to the Faculty of Nursing, Universitas Padjadjaran, which allowed this study to be undertaken and the Directorate of Research and Community Service of Universitas Padjadjaran which provided research funding support. In addition, I would like to thank all of the participants who took part in this study.

\section{REFERENCES}

Aglen, B. (2016). Pedagogical strategies to teach bachelor students evidence-based practice: A systematic review. Nurse Education Today, 36(Supplement C), pp.255-263. doi: https://doi.org/10.1016/j.nedt.2015.08.025

Azmoude, E., Farkhondeh, F., Ahour, M., \& Kabirian, M. (2017). Knowledge, Practice and Self-Efficacy in Evidence-Based Practice among Midwives in East Iran. Sultan Qaboos University Medical Journal, 17(1), e66-e73. doi: 10.18295/squmj.2016.17.01.012

Bandura, A. (1977). Self-efficacy: toward a unifying theory of behavioral change. Psychological Review, 84(2), p.191.

Bloom, K. C., Olinzock, B. J., Radjenovic, D., \& Trice, L. B. (2013). Leveling EBP content for undergraduate nursing students. Journal of Professional Nursing, 29(4), pp.217-224.

Elysabeth, D., Libranty, G., \& Natalia, S. (2015). Hubungan tingkat pendidikan perawat dengan kompetensi aplikasi evidence-based practice correlation between nurse's education level with the competency to do evidence-based practice. Jurnal Skolastik Keperawatan, 1(01).

Farokhzadian, J., Khajouei, R., \& Ahmadian, L. (2015). Evaluating factors associated with implementing evidence-based practice in nursing. Journal of Evaluation in Clinical Practice, 21(6), 1107-1113. doi: $10.1111 /$ jep. 12480

Farokhzadian, J., Khajouei, R., \& Ahmadian, L. (2015). Evaluating factors associated with implementing evidence-based practice in nursing. Journal of Evaluation in Clinical Practice, 21(6), pp.11071113.

Häggman-Laitila, A., Mattila, L.-R., \& Melender, H.-L. (2016). Educational interventions on evidencebased nursing in clinical practice: a systematic review with qualitative analysis. Nurse Education Today, 43, p.50-59.

Hande, K., Williams, C. T., Robbins, H. M., Kennedy, B. B., \& Christenbery, T. (2017). Leveling Evidencebased Practice Across the Nursing Curriculum. The Journal for Nurse Practitioners, 13(1), e17-e22.

Khammarnia, M., Haj Mohammadi, M., Amani, Z., Rezaeian, S., \& Setoodehzadeh, F. (2015). Barriers to implementation of evidence-based practice in Zahedan teaching hospitals, Iran, 2014. Nursing Research and Practice, 2015. 
Legita, T. (2012). Pengetahuan, Sikap dan Kesiapan Perawat Klinisi Dalam Implementasi EvidenceBase Practice. NERS Jurnal Keperawatan, 8(1), pp.84-97.

Mashiach Eizenberg, M. (2011). Implementation of evidence-based nursing practice: nurses' personal and professional factors? Journal of advanced nursing, 67(1), pp.33-42.

Masters, K. (2015). Role Development in Professional Nursing Practice. Jones \& Bartlett Publishers.

Melnyk, B. M., Fineout-Overholt, E., Stillwell, S. B., \& Williamson, K. M. (2010). Evidence-based practice: step by step: the seven steps of evidencebased practice. The American Journal of Nursing, 110(1), pp.51-53.

Melnyk, B. M., Gallagher-Ford, L., Long, L. E., \& Fineout-Overholt, E. (2014). The establishment of evidence-based practice competencies for practicing registered nurses and advanced practice nurses in real-world clinical settings: proficiencies to improve healthcare quality, reliability, patient outcomes, and costs. Worldviews on Evidence-Based Nursing, 11(1), pp.5-15.

Mohsen, M. M., Safaan, N. A., \& Okby, O. M. (2016). Nurses' perceptions and barriers for adoption of evidence-based practice in primary care: Bridging the gap. American Journal of Nursing Research, 4(2), pp.25-33.
Oh, E. G., Yang, Y. L., Sung, J. H., Park, C. G., \& Chang, A. M. (2016). Psychometric Properties of Korean Version of Self-Efficacy of Evidence-Based Practice Scale. Asian Nursing Research, 10(3), pp.207-212.

Ryan, E. J. (2016). Undergraduate nursing students' attitudes and use of research and evidence-based practice-an integrative literature review. Journal of Clinical Nursing, 25(11-12), 1548-1556.

Shinnick, M. A., \& Woo, M. A. (2014). Does Nursing Student Self-efficacy Correlate with Knowledge When Using Human Patient Simulation? Clinical Simulation in Nursing, 10(2), e71-e79.

Sin, M.-K., \& Bliquez, R. (2017). Teaching evidencebased practice to undergraduate nursing students. Journal of Professional Nursing.

Stevens, K. R. (2009). Essential competencies for evidence-based practice in nursing. Academic Center for Evidence-Based Practice, University of Texas Health Science Center at San Antonio.

Suba, S., \& Scruth, E. A. (2015). A new era of nursing in Indonesia and a vision for developing the role of the clinical nurse specialist. Clinical Nurse Specialist, 29(5), 255-257.

Upton, D., \& Upton, P. (2006). Development of an evidence-based practice questionnaire for nurses. Journal of Advanced Nursing , 53(4), pp.454-458. doi: 10.1111/j.1365-2648.2006.03739.x 